\title{
Habitat damage, marine reserves, and the value of spatial management
}

\author{
Holly V. Moeller ${ }^{1}$ and Michael G. Neubert ${ }^{2}$ \\ Biology Department, MS 34, Woods Hole Oceanographic Institution, Woods Hole, Massachusetts 02543-1049 USA
}

\begin{abstract}
The biological benefits of marine reserves have garnered favor in the conservation community, but "no-take" reserve implementation is complicated by the economic interests of fishery stakeholders. There are now a number of studies examining the conditions under which marine reserves can provide both economic and ecological benefits. A potentially important reality of fishing that these studies overlook is that fishing can damage the habitat of the target stock. Here, we construct an equilibrium bioeconomic model that incorporates this habitat damage and show that the designation of marine reserves, coupled with the implementation of a tax on fishing effort, becomes both biologically and economically favorable as habitat sensitivity increases. We also study the effects of varied degrees of spatial control on fisheries management. Together, our results provide further evidence for the potential monetary and biological value of spatial management, and the possibility of a mutually beneficial resolution to the fisherman-conservationist marine reserve designation dilemma.
\end{abstract}

Key words: bioeconomics; destructive fishing practices; fisheries; habitat damage; marine protected areas; marine reserves; optimal control; optimal harvesting; spatial management.

\section{INTRODUCTION}

The overexploitation of many marine fish stocks, despite intense regulation, has caused fisheries scientists and economists to examine the relative effectiveness of alternative management forms. One form, the establishment of permanent "no-take" marine reserves, has garnered particular favor with the conservation community. Where reserves have been successfully established, they have rapidly become sanctuaries for elevated stock biomass and population density, shown elevated levels of biodiversity, and protected intact habitat relative to adjacent fished areas (reviewed in Halpern and Warner 2003 and Lester et al. 2009). However, reserves may face steep opposition when closures are perceived as economically costly.

The prohibition of fishing in a reserve removes any enclosed stock biomass from harvester access, and forces fishermen to either reduce overall effort, or intensify fishing elsewhere (Smith and Wilen 2003). Nevertheless, many bioeconomic analyses indicate that the establishment of marine reserves can have both economic and biological benefits (see Plate 1). Whether reserves are economically optimal depends upon the cost of fishing and species life history. In particular, reserves are more likely to be economically efficient when they are net

Manuscript received 19 March 2012; revised 20 November 2012; accepted 28 November 2012. Corresponding Editor: M. D. Smith.

${ }^{1}$ Present address: Department of Biology, 371 Serra Mall, Stanford, California 94305 USA.

${ }^{2}$ Corresponding Author. E-mail: mneubert@whoi.edu exporters of larvae or harvestable biomass (Gerber et al. 2003, Sanchirico et al. 2006, White and Kendall 2007; but see Gårdmark et al. [2006] for an exception), when they encompass areas that would be costly to fish in their absence (Smith and Wilen 2003, Sanchirico et al. 2006), or when fish stocks are already overexploited (Gerber et al. 2003).

In many of the models used to reach these conclusions, the spatial dimension is represented implicitly and reserves are designated as a fixed fraction of habitat - and thus a fixed fraction of the stock - that is closed to fishing. For a range of reserve sizes, stock biomass and fishing intensity are then calculated to maximize yield or profit (Gerber et al. 2003; see Gårdmark et al. 2006 and White and Kendall 2007 for examples). An alternative modeling strategy begins with a spatially explicit model (e.g., a partial differential equation) describing the population dynamics of a stock living in continuous habitat. The spatial distribution of effort is then calculated according to economic assumptions about the property rights and behavior of fishermen. The optimality of reserves may emerge from this analysis when fished species are mobile and habitat is heterogeneous (Neubert 2003, Costello and Polasky 2008).

Whatever form these theoretical analyses have taken, they have almost all neglected the potential for habitatdamaging effects of fishing (Armstrong and FalkPetersen 2008). Fishing-driven habitat damage may reduce the habitat's ability to support fish stocks through biomass removal and reduction in habitat complexity (Fogarty 2005, Hiddink et al. 2006b). 
Modeling and empirical evidence suggest that habitats may display a wide range of sensitivities to damage from fishing gear (Auster 1998, Watling and Norse 1998, Fogarty 2005, Hiddink et al. 2006a, b), and it has been suggested that reserves may be more economically effective when protecting the most vulnerable habitat (National Research Council 2001, Hiddink et al. 2007).

This raises the question: Can no-take reserves be optimal (i.e., revenue maximizing) when fishing damages the habitat of the targeted stock?

While a number of published studies touch on the relationship between habitat quality and the economic benefits of reserves, to our knowledge none addresses this question directly. In some analyses (Rodwell et al. 2003, Sanchirico 2004, Armstrong and Skonhoft 2006, Armstrong 2007), habitat inside a reserve is better for the protected stock (e.g., has increased carrying capacity or lower natural mortality) than habitat that is outside of the reserve - even when there is no fishing outside of the reserve. The damage that occurs to habitat outside of the reserves in these models, therefore, cannot be due to fishing (at least not fishing on the target stock). Mangel (2000) studied a model in which habitat destruction occurring outside of a protected area occurs randomly and is independent of fishing effort. Holland and Schnier (2006) studied the efficacy of an "individual habitat quota" system for managing the deleterious impact of fishing on essential fish habitat, but in their models habitat quality does not affect the vital rates of the stock species.

So the question of reserve optimality in the face of habitat damage remains. To address this question, we consider a model in which the habitat damage generated by fishing decreases the quantity or quality of spatial resources. Intraspecific competition subsequently intensifies, reducing the birth rate or increasing the mortality rate of the harvested species (Lindholm et al. 2001). In this study, we consider a range of habitat sensitivities to fishing (Auster 1998).

We analyze this model from several economic perspectives. First, we consider an unmanaged baseline: the "open-access" case, in which effort equilibrates at a level that dissipates profit at every location (Sanchirico and Wilen 1999). We contrast this unregulated system with three tax-based management strategies: (1) a nonspatial tax strategy, in which the manager taxes each unit of effort equally; (2) a tax and reserve strategy, in which the manager designates a centrally located fishery closure and taxes every unit of effort outside the reserve equally; and (3) a spatial tax strategy, in which the manager taxes fishing effort differentially based on its spatial location.

We choose a tax-based management scheme for its mathematical convenience. The results we obtain, however, could be duplicated, in principle, using a variety of other policy instruments (e.g., individual catch quotas, or enforced closures). Our analysis of multiple management strategies allows us to assess the value of spatial knowledge, and determine the management consequences of varying degrees of spatial control. The "spatial-tax" case, while possibly difficult to implement in the real world, provides a reference case against which lesser degrees of management can be measured.

In each case, we find the management action that maximizes the tax revenue collected by the manager. The spatial distribution of effort that results is equivalent to the distribution that would maximize rent to a sole owner (Appendix A). Thus, maximizing tax revenue is equivalent, in our model, to maximizing rent.

We demonstrate improvements in tax revenue and standing stock biomass as the manager's degree of spatial control improves. We also show that the inclusion of habitat-damaging fishing effects in this model increases the range of ecological and economic conditions under which marine reserves are part of an optimal (revenue-maximizing) management strategy.

\section{The Model}

We build on the model of Neubert and Herrera (2008), who consider a stock whose population density $N$ at location $X$ and time $T$ changes as a result of local population growth, diffusion, and harvesting. In one spatial dimension, such a stock evolves in time according to the following partial differential equation:

$$
\frac{\partial N}{\partial T}=g(N)+D \frac{\partial^{2} N}{\partial X^{2}}-q E(X) N
$$

where $g$ is the rate of population growth and $D$ is the diffusion coefficient. Let us assume that harvesting occurs at a rate that is proportional to both the stock density and the effort density, $E(X)$. The "catchability coefficient," $q$, is the proportionality constant.

At equilibrium $\partial N / \partial T=0$, so we may write $N(X, T)=$ $N(X)$, and Eq. 1 becomes

$$
D \frac{\partial^{2} N}{\partial X^{2}}=q E(X) N-g(N) .
$$

Since suitable habitat for any real stock is finite, we assume that fish cannot survive outside of a stretch of habitat of length $L$. That is, $N(X)=0$ for $|x|>L / 2$. Since we expect $N(X)$ to be continuous, we impose the following boundary conditions:

$$
N(-L / 2)=N(L / 2)=0 .
$$

That is, the fish population density drops to zero at the habitat edges. We consider alternative boundary conditions in a subsequent section.

In our model, habitat quality is reflected in the birth and mortality rates $b(N)$ and $d(N)$ that comprise the function $g$ :

$$
g(N)=[b(N)-d(N)] N .
$$

So that the population will not grow without bound, we posit that the birth rate declines with population density while the mortality rate grows with population density 
(Sinclair 1989), i.e.,

$$
b(N)=b_{0}-b_{1} N \text { and } d(N)=d_{0}+d_{1} N .
$$

Combining Eq. 5 with Eq. 4 results in logistic population growth in the absence of harvesting.

To capture the habitat-damaging effects of fishing we next assume that as fishing effort increases, densitydependent effects are intensified, as by increased competition between individual fish for resources like food, shelter, or spawning area. We model this effect by positing linear increases in $b_{1}$ and $d_{1}$ with increasing effort (Auster 1998), and replace $g(N)$ in Eqs. 1 and 2 with

$$
g(N, E)=\left[b_{0}-d_{0}-\left(b_{1}+d_{1}+h E\right) N\right] N .
$$

We call the constant $h$ the habitat sensitivity. Its value will in general depend upon the nature of the habitat (e.g., the complexity and resilience of the biotic and abiotic structures), upon the fishing gear employed, upon the features of the habitat damaged by that gear, and upon how those habitat features are used by the target species (e.g., as a nursery, refuge, feeding ground, and so forth).

In our model, the level of fishing effort at any location results from the collective activity of a large number of harvesters who decide to enter or exit the fishery based upon the possibility of making a profit. In the face of a fixed price $p$, the profit generated at location $X$ is the difference between the total revenue at location $X$,

$$
\operatorname{TR}(X)=p q E(X) N(X)
$$

and the total cost of fishing at location $X, \mathrm{TC}(X)$.

Let us assume that the cost per unit effort at a given location is $w_{0}+w_{1} E(x)$, where $w_{0}$ is the cost of the first unit of effort. Costs increase at the rate $w_{1}$, reflecting the increasing costs that harvesters impose upon one another when more of them try to fish in the same location. If fishermen must also pay a tax per unit effort, $\mathcal{T}(X)$, the total cost at location $X$ is given by

$$
\mathrm{TC}(X)=\left[w_{0}+w_{1} E(X)+\mathcal{T}(X)\right] E(X) .
$$

Subtracting the total cost (Eq. 8) from the total revenue (Eq. 7) gives the revenue density (i.e., the profit per unit habitat length)

$$
R(X)=p q E(X) N(X)-\left[w_{0}+w_{1} E(X)+\mathcal{T}(X)\right] E(X) .
$$

We will assume that the fishery has "open access," and that fishing effort at any location equilibrates so that the revenue density (Eq. 9) vanishes at every location (Sanchirico and Wilen 1999). The simultaneous solution of the equilibrium condition (Eq. 2) and the open access condition, $R(X)=0$, determines the effort density and stock density that would result from any specification of the $\operatorname{tax} \mathcal{T}(X)$.

\section{Maximizing tax revenues}

Now we take the perspective of the fisheries manager, whose objective is to maximize tax revenue $(\mathcal{P})$

$$
\mathcal{P}(\mathcal{T}(X))=\int_{-L / 2}^{L / 2} \mathcal{T}(X) E(X) d X
$$

by choosing the best tax distribution subject to regulatory constraints. We imagine that these constraints might take three forms: In the first form (Case I), any tax the manager imposes must be the same at every location. That is, $\mathcal{T}(X)=\mathcal{T}_{\text {ns }}$, where $\mathcal{T}_{\text {ns }}$ is a nonnegative constant. We will call this a "nonspatial tax." As an alternative (Case II), which we will call "tax and reserve," the manager may choose to supplement the nonspatial effort $\operatorname{tax}\left(\mathcal{T}_{\mathrm{ns}}\right)$ with a single, centrally located spatial reserve of length $L_{\mathrm{r}}$ within which fishing is prohibited. Under the least restrictive alternative (Case III), the manager is free to choose a different tax rate at every spatial location (as long as $\mathcal{T}(X)$ is a nonnegative piecewise-continuous function). We will call this a "spatial tax."

The solution of the manager's optimization problem in Cases I and II can be found by direct searches (over $\mathcal{T}_{\text {ns }}$ in Case I; over $\mathcal{T}_{\text {ns }}$ and $L_{\mathrm{r}}$ in Case II). The solution in Case III involves methods from optimal control theory which we develop in Appendix A.

Before we report the results of our analysis, note that our model has 12 parameters. However, the change of variables

$$
\begin{aligned}
& u=\frac{b_{1}+d_{1}}{b_{0}-d_{0}} N \\
& t=\left(b_{0}-d_{0}\right) T \\
& x=\sqrt{\frac{b_{0}-d_{0}}{D} X} \\
& \tau=\frac{b_{1}+d_{1}}{p q\left(b_{0}-d_{0}\right)} \mathcal{T} \\
& f=\frac{q}{b_{0}-d_{0}} E \\
& \mathcal{R}=\frac{b_{1}+d_{1}}{p\left(b_{0}-d_{0}\right)^{2}} R \\
& \Pi=\frac{b_{1}+d_{1}}{p \sqrt{\left(b_{0}-d_{0}\right)^{3} D}} \mathcal{P}
\end{aligned}
$$

shows that the model actually only depends upon the six dimensionless parameter groups:

$$
\begin{gathered}
\ell=\sqrt{\frac{b_{0}-d_{0}}{D}} L \\
\gamma=\frac{h\left(b_{0}+d_{0}\right)}{q\left(b_{1}+d_{1}\right)} \\
\omega_{0}=\frac{w_{0}\left(b_{1}+d_{1}\right)}{p q\left(b_{0}-d_{0}\right)}
\end{gathered}
$$




$$
\begin{gathered}
\omega_{1}=\frac{w_{1}\left(b_{1}+d_{1}\right)}{p q^{2}} \\
\tau_{\mathrm{ns}}=\frac{b_{1}+d_{1}}{p q\left(b_{0}-d_{0}\right)} \mathcal{T}_{\mathrm{ns}} \\
\ell_{\mathrm{r}}=\sqrt{\frac{b_{0}-d_{0}}{D}} L_{r} .
\end{gathered}
$$

(See Appendix A for the dimensionless version of the model.) In the results that follow, we hold constant the rescaled habitat size (at $\ell=15$ ) and the rescaled costs (at $\omega_{0}=0.01$ and $\left.\omega_{1}=0.001\right)$ and examine how habitat sensitivity $(\gamma)$ affects the relative tax revenues that can be produced under the three regulatory cases. We report equilibrium results from the model. Our numerical simulations suggest that these emerge regardless of initial conditions.

\section{RESUlts}

\section{Unmanaged baseline}

When the fishery is unmanaged (i.e., $\tau_{\mathrm{ns}}=0$ and $\ell_{\mathrm{r}}=$ 0 ), fishing effort is constant in the central portion of the habitat, and drops to zero near the habitat edges, where stock density is low because fish are leaving the habitat (Fig. 1a). The size of these unfished edge regions depends upon the economic balance between catch value and the cost of obtaining the catch, which together determine a threshold stock density below which fishing is uneconomical. This threshold density varies with our choices of $\omega_{0}$ (the cost of the first unit of effort) and $\omega_{1}$ (the rate of increase of cost), but changes to these parameters (particularly $\omega_{1}$, which we varied over several orders of magnitude) did not qualitatively change our results.

As habitat sensitivity increases, habitat quality degrades under unrestricted effort, reducing the local population density and, consequently, the local effort density (Fig. 1b). Although the spatial distributions of fish biomass and fishing effort do not change qualitatively with increasing habitat sensitivity, their spatially integrated values, as well as the total yield, decline as habitat becomes more sensitive to fishing damage (Fig. 1c).

\section{Case I. Nonspatial effort tax}

The imposition of a nonspatial tax reduces effort throughout the habitat (Fig. 2, compare panels a and d) because harvesters experience an additional cost per unit effort (effectively increasing $\omega_{0}$ ). The edge unfished areas increase in size because a higher stock density is required to support any fishing effort under these increased costs. The tax-induced effort reductions result in higher stock densities throughout the habitat.

The optimal tax rate is chosen to maximize the tax revenue collected by the manager, and represents a trade-off between increasing revenue per unit effort, and
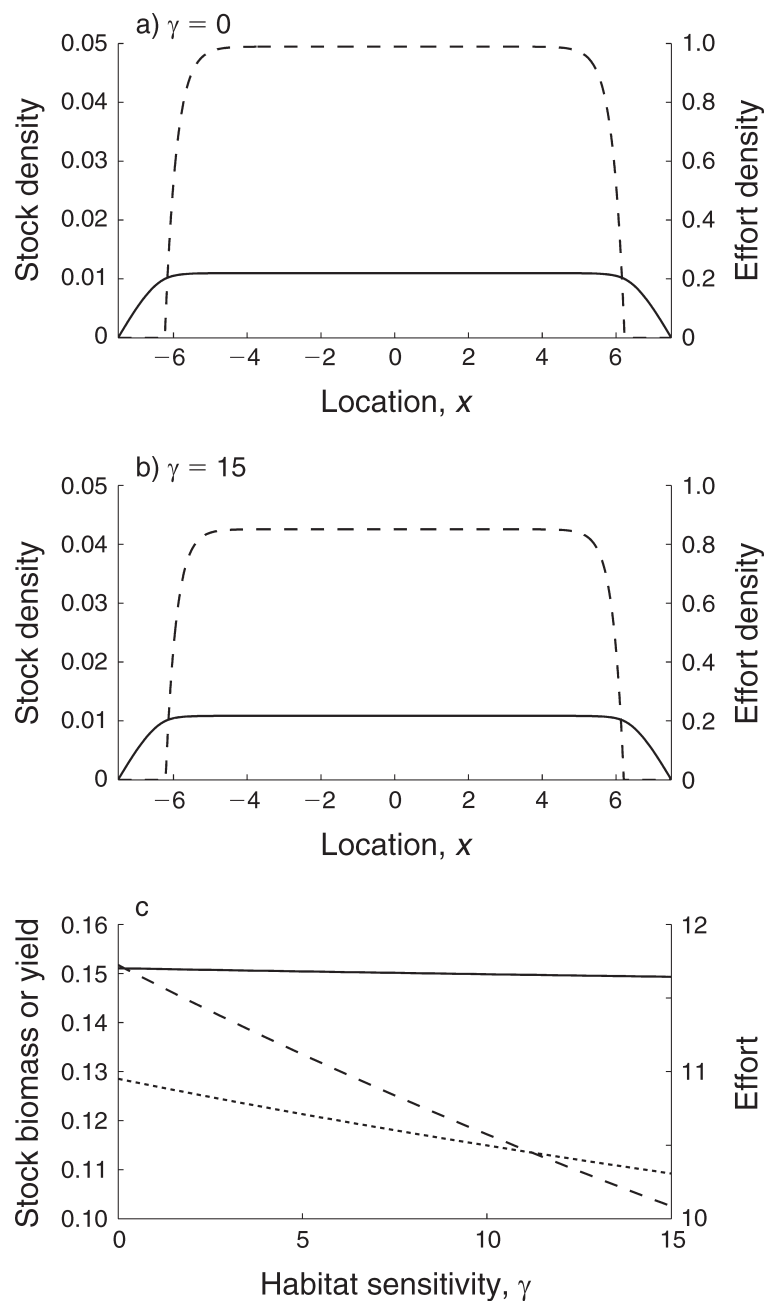

FIG. 1. Effects of habitat sensitivity on the unmanaged baseline. ( $a, b)$ Spatial distributions of stock density (solid line) and effort density (dashed line) in the absence of any management for habitat sensitivity $\gamma=0$ and $\gamma=15$, respectively. (c) Effort (i.e., the effort density integrated from 0 to $\ell$, dashed line), stock biomass (i.e., the stock density, integrated from 0 to $\ell$, solid line), and yield (dotted line) in the unmanaged case. For all three panels in this figure, we set the habitat length $(\ell)$ to 15 , and the cost parameters $\omega_{0}$ and $\omega_{1}$ to 0.01 and 0.001 , respectively; the tax per unit effort $\tau=0$. All plotted quantities are unitless.

decreasing levels of effort with increasing tax rates (Fig. $2 \mathrm{~g}-\mathrm{i})$. Habitat damage reduces the productivity of the fishery, and therefore reduces the profitability per unit fishing effort, in turn reducing total effort. The manager compensates for the reductions in effort (and therefore tax revenue) by lowering the tax rate (Fig. 3). This reduction in tax rate opens a slightly larger fraction of habitat to fishing (i.e., the unfished habitat edge margin decreases) because the cost per unit effort experienced by fishermen is lowered and, therefore, the threshold 
TABLE 1. Explanations of the variables and parameters used in our study, together with their typical units

\begin{tabular}{|c|c|c|c|}
\hline Symbol & Description & Units & $\begin{array}{c}\text { Dimensionless } \\
\text { version }\end{array}$ \\
\hline \multicolumn{4}{|l|}{ Variables } \\
\hline X & space & $\mathrm{km}$ & $x$ \\
\hline$T$ & time & $\mathrm{yr}$ & $t$ \\
\hline$N(X, T)$ & stock density & tonnes $/ \mathrm{km}$ & $u(x, t)$ \\
\hline$E(X)$ & effort density & vessel days $\cdot \mathrm{km}^{-1} \cdot \mathrm{yr}^{-1}$ & $f(x)$ \\
\hline$R(X)$ & revenue density & dollars $\cdot \mathrm{yr}^{-1} \cdot \mathrm{km}^{-1}$ & $\mathcal{R}(x)$ \\
\hline $\mathcal{T}(X)$ & effort tax & dollars/vessel day & $\tau(x)$ \\
\hline$P$ & equilibrium tax revenue & & $\Pi$ \\
\hline \multicolumn{4}{|c|}{ Parameters } \\
\hline$b_{0}$ & low-density birth rate & $\mathrm{yr}^{-1}$ & \\
\hline$d_{0}$ & low-density mortality rate & $\mathrm{yr}^{-1}$ & \\
\hline$b_{1}$ & density-dependent birth rate & tonne $\mathrm{e}^{-1} \cdot \mathrm{yr}^{-1}$ & \\
\hline$d_{1}$ & density-dependent mortality rate & tonnes ${ }^{-1} \cdot \mathrm{yr}^{-1}$ & \\
\hline$h$ & habitat sensitivity & $\mathrm{km} \cdot$ tonne $^{-1} \cdot \mathrm{yr}^{-1}$ & $\gamma$ \\
\hline$D$ & diffusion coefficient & $\mathrm{km}^{2} / \mathrm{yr}$ & \\
\hline$L$ & habitat length & $\mathrm{km}$ & $\ell$ \\
\hline$L_{\mathrm{r}}$ & reserve length & $\mathrm{km}$ & $\ell_{\mathrm{r}}$ \\
\hline$q$ & catchability coefficient & $\mathrm{km} /$ vessel day & \\
\hline$p$ & price & dollars/tonne & \\
\hline$w_{0}$ & effort cost & dollars/vessel day & $\omega_{0}$ \\
\hline$w_{1}$ & congestion cost & dollars $(\text { vessel day })^{-2} \cdot \mathrm{km} \cdot \mathrm{yr}$ & $\omega_{1}$ \\
\hline $\mathcal{T}_{\text {ns }}$ & nonspatial effort tax & dollars/vessel day & $\tau_{\mathrm{ns}}$ \\
\hline
\end{tabular}

Notes: "Stock density" is the same as "biomass density"; "effort density" is the same as "fishing density." SI conversion: 1 tonne $=1000 \mathrm{~kg}=1 \mathrm{Mg}$.
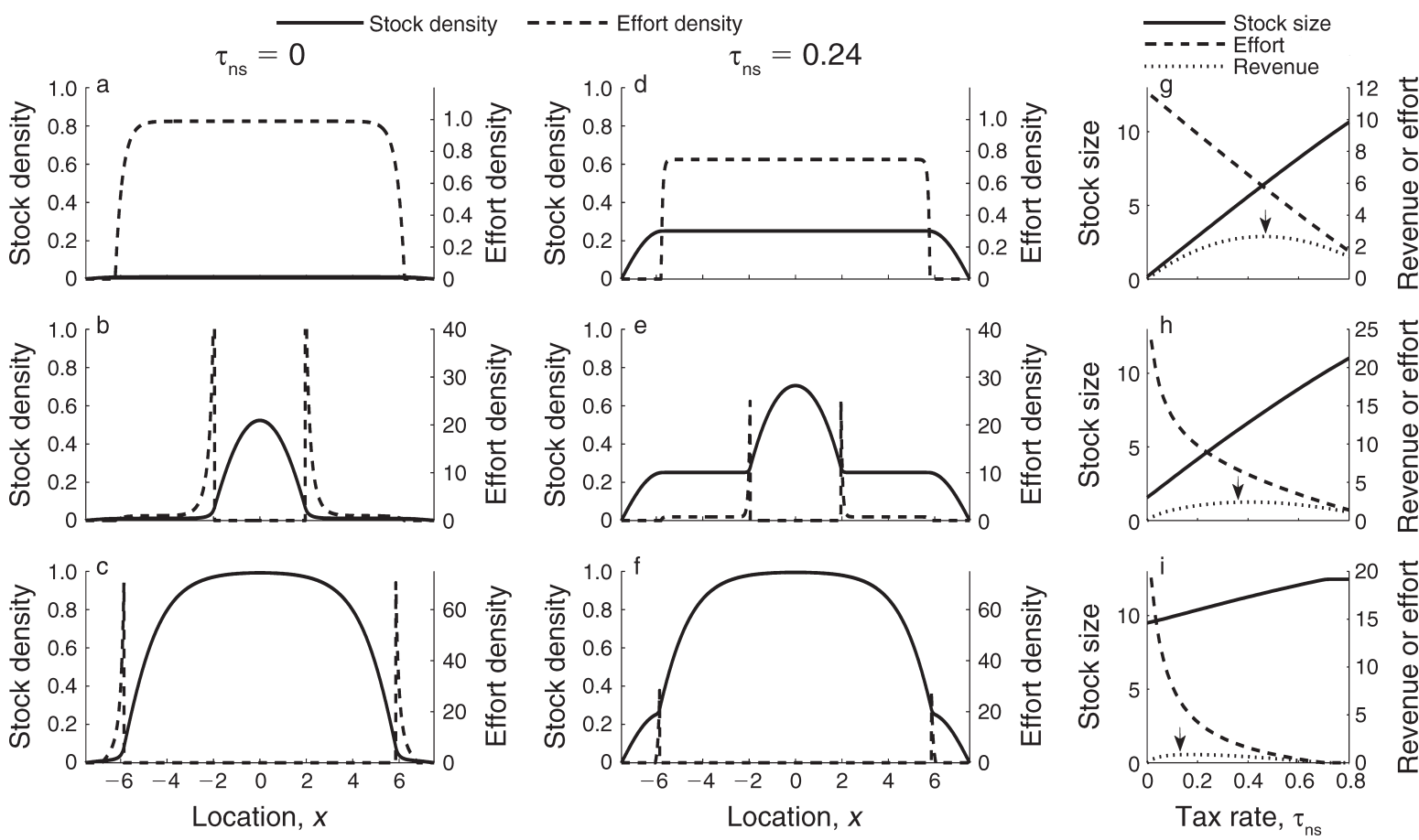

FIG. 2. How management strategies work. (a-c) These left-hand panels show the effects of increasing central reserve size: effort (dashed line) is displaced to the habitat edges, and piles up at the reserve edges to capture any fish exiting the undamaged habitat. Stock populations thrive in the reserve: their size approaches the carrying capacity when the reserves is sufficiently large [as in panel (c)]. (d-f) The central column shows the effects of the addition of a nonspatial tax $\left[\tau_{\mathrm{ns}}=0\right.$ in panels (a)-(c); $\tau_{\mathrm{ns}}=0.24$ in panels (d)(f). This tax reduces effort everywhere within the habitat. (g-i) As the tax rate increases, total effort decreases (dashed line), and total stock recovers (solid line). For a given reserve size, the manager should select the tax rate that maximizes revenues (dotted line). As reserve size increases, the optimal tax rate (indicated by the black arrow) decreases. 


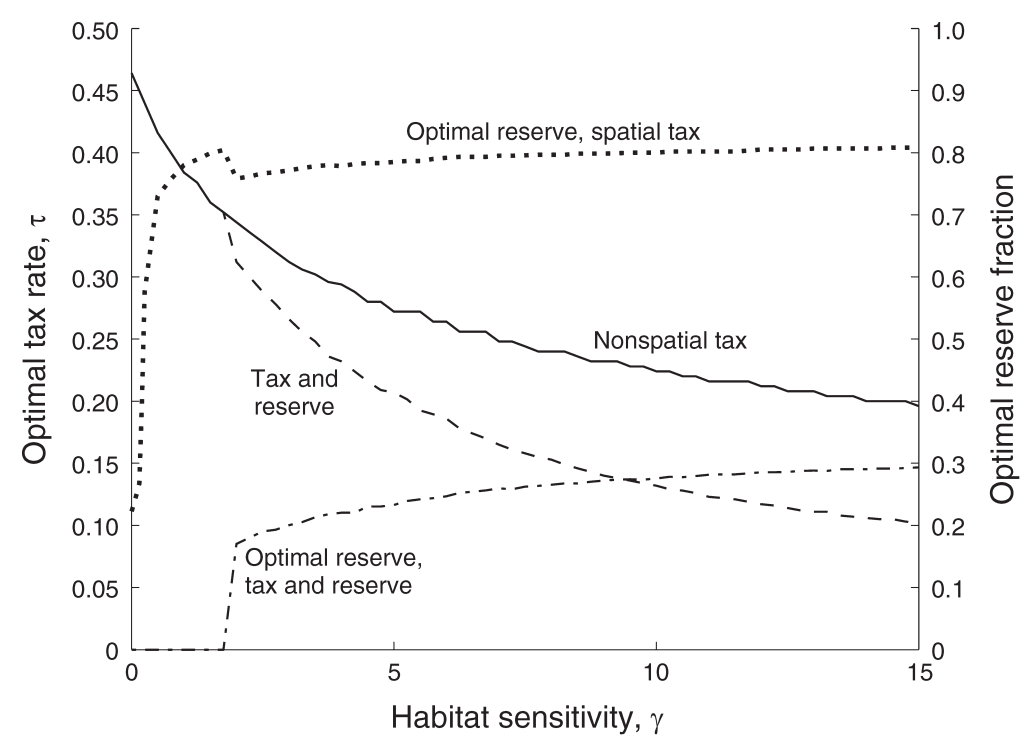

FIG. 3. Optimal tax levels under "nonspatial-tax" (solid line) and "tax-and-reserve" (dashed line) management strategies, and corresponding reserve fractions for varying habitat sensitivities. The manager responds to increasing habitat sensitivity by lowering tax rates, effectively opening more of the habitat for fishing. When reserves are available, the fraction of habitat placed in reserve increases with increasing habitat sensitivity and enables the use of a lower tax rate. The optimal habitat fraction in reserve for the "spatial-tax" case is also shown (dotted line), and is much larger than the optimal reserve fraction under "tax-and-reserve" management (dot-dash line).

biomass density at which fishing occurs is also reduced (Fig. 4a-e).

In general, in more sensitive (i.e., higher $\gamma$ ) habitats, the optimal effort density is lower and the area over which the effort is distributed is slightly larger (Fig. 4ae) when taxes cannot be adjusted spatially.

\section{Case II. Nonspatial effort tax with reserve}

When the management strategy includes a single reserve, that reserve provides a refuge that supports elevated biomass densities (Fig. 2b, c). Effort piles up on the reserve edges, where fishermen "fish the line" (Kellner et al. 2007) to capture any fish that are leaving the reserve.

Again, the manager's goal is to maximize tax revenue (Fig. 2e, f), in this case by balancing loss of fishing area and, thus, lost taxable effort, with increased stock size, which supports elevated fishing effort outside the reserve.

In this case, we find that reserve establishment is optimal only when habitat sensitivity is sufficiently high $(\gamma>1.25$; Figs. 3 and $4 \mathrm{f}-\mathrm{j})$. By using reserves, the manager can protect fish populations within a central region of the habitat, resulting in elevated effort levels at reserve edges, where fishermen compete to catch spillover (Fig. 4f-j). Because the manager has a twopronged management mechanism, he or she can also set a lower tax rate than is possible with a flat effort tax alone (Fig. 3). Thus, optimal tax is inversely related to the fraction of habitat in reserve.

\section{Case III. Spatially variable effort tax}

When fishing does not damage habitat $(\gamma=0)$, we find that the optimal spatial tax produces an effort distribution that includes unfished areas at the habitat edges, where biomass density is low (Fig. 4k). Just inside of these low-biomass regions, however, fishing intensity is highest, as the fishermen attempt to capture fish before they swim out of the habitat and are lost. The manager encourages these efforts by lowering the tax rate as the stock density declines toward the habitat edges (Appen$\operatorname{dix}$ A: Fig. A1). The center of the habitat is fished at a low but constant effort level, and is flanked by reserves enforced by higher tax levels, where stock density is slightly elevated. The emergence of these reserves has been reported before (Neubert and Herrera 2008), and provides evidence of the importance of spatial management.

As we incorporate habitat damage, these reserves expand and reserve networks of fixed size emerge as the optimal management strategy (Fig. 41-o). By establishing reserve networks, the manager restricts habitat damage to relatively narrow fished zones and sets aside up to $80 \%$ of habitat in reserves (Fig. 3, dotted line). The adjacent reserves support elevated biomass density, which then spills over into the fished areas.

To test for the role of edge effects in driving this network pattern, we repeated our analysis for a variety of habitat lengths (Fig. 5). Note that, because of our model rescaling (Eq. 12), increasing habitat size could represent either actual increases in spatial habitat extent, or decreases in fish movement rates in the original 


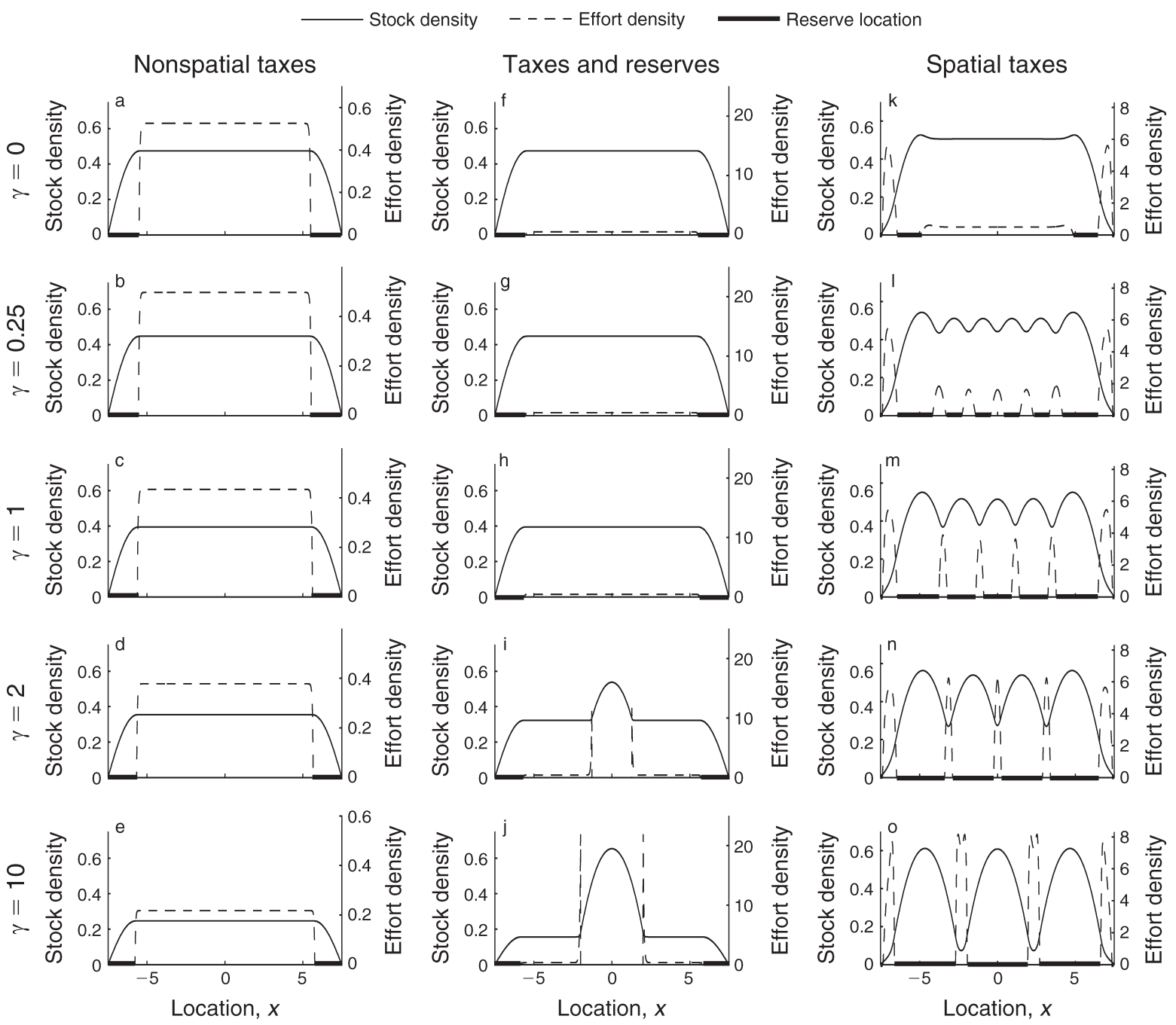

FIG. 4. The spatial distributions of stock density (solid line) and fishing effort (dashed line) under (a-e) optimal "nonspatialtax," (f-j) "tax-and-reserve," and ( $\mathrm{k}-\mathrm{o}$ ) "spatial-tax" management strategies, shown for increasing habitat sensitivities, $\gamma$ (values 0 10 from rows $1-5)$. Reserve locations are indicated by thick $x$-axes. Note the differing magnitudes of effort axes across management strategies. Under full spatial management ("spatial tax"; Case III), reserve networks emerge as optimal as habitat sensitivity increases.

model. We found that reserve networks emerged at any habitat length larger than the period of the reserve network. Furthermore, the network period was constant for habitats large enough to support reserve networks.

We also tested an alternative formulation for habitat damage, in which fish experience a habitat feedback through a reduction in density-independent vital rates (Appendix B). Intriguingly, marine reserve networks did not emerge in this alternative model formulation under spatial tax management (Appendix B: Fig. B2), although full spatial management was most economically efficient (Appendix B: Fig. B3).

\section{Comparison of Management EfFects}

Economically optimal solutions differ across management strategies, leading to marked differences in total stock biomass, fishery yield, fishing effort, and tax revenue. By comparing the results of the various management strategies to one another, and to the unmanaged baseline case, we can quantify the relative economic and biological gains of spatial management.

Any form of management produces significant bioeconomic benefits by supporting elevated stock and catch levels (Fig. 6a, b). Full spatial control, as in the best-case "spatial-tax" strategy, produces the largest gains, though any form of reserve designation allows stock biomass and fishery yield to increase relative to the "nonspatial-tax" management strategy. Although the introduction of reserve networks can briefly bolster fish populations in the face of increasing habitat sensitivity (Fig. 6a), as habitat sensitivity increases both standing stock (stock biomass) and fishery yield decline. 

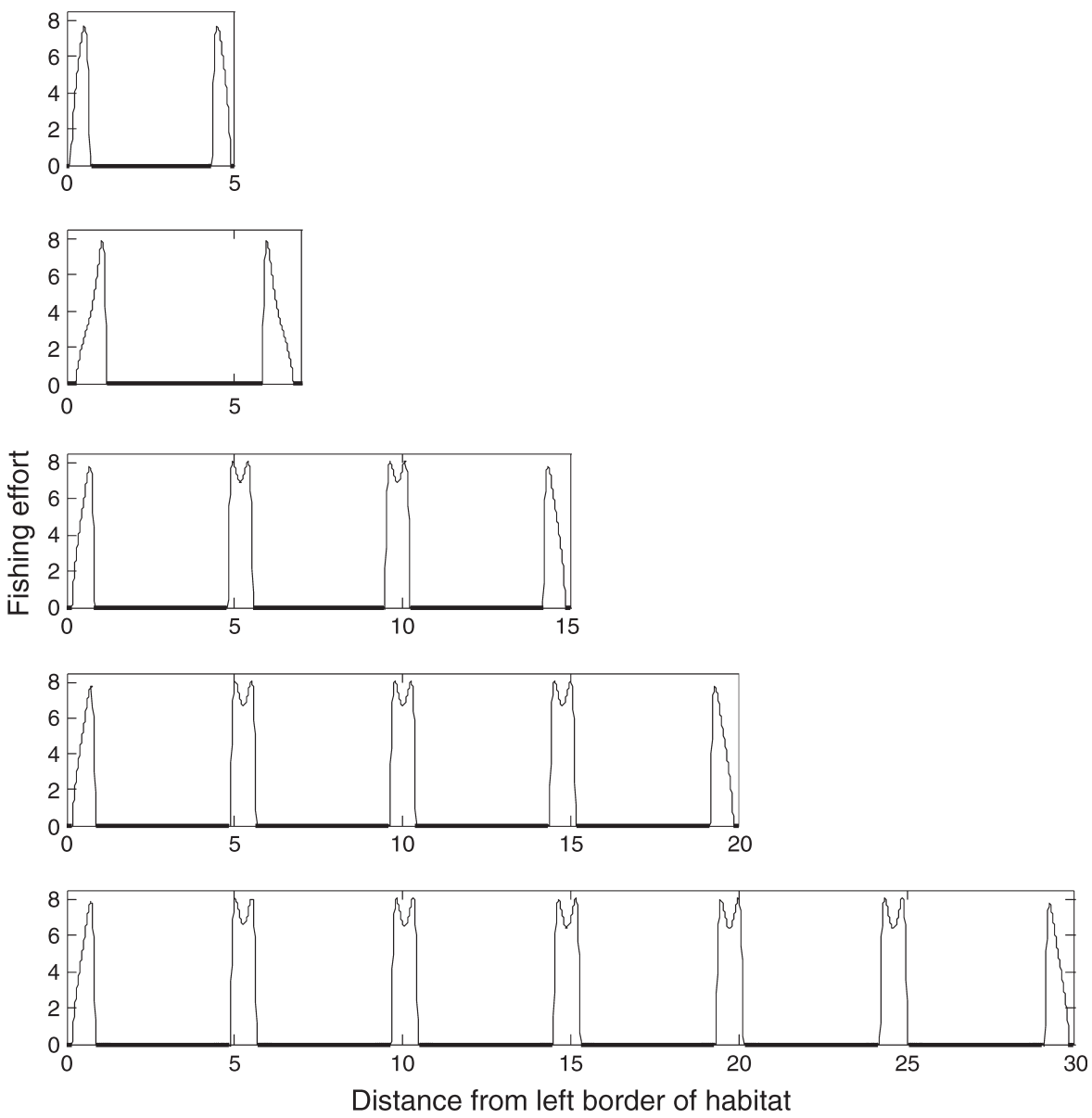

FIG. 5. Optimal effort distribution for various habitat lengths under "spatial-tax" management. Parameter values are $\omega_{0}=0.01$, $\omega_{1}=0.001$, and $\gamma=15$. Note the emergence of "reserve networks," with alternating reserves and fished areas. Each reserve (heavy $x$ axis line) is of the same length and is separated from the adjacent reserve by a fished area, also of uniform length. The sum of these two lengths is the "network period."

"Spatial-tax" management also supports elevated total effort levels relative to the unmanaged baseline, particularly when multiple reserves are used, concentrating heavy fishing into narrow bands between reserves (Fig. 41-o). These high effort levels are sustained for a wide range of habitat sensitivities - and in some cases, increasing habitat sensitivity actually leads to elevated total effort levels under optimal "spatial-tax" management (Fig. 6c). Generally, increasing habitat sensitivity produces only modest declines in total effort for any of the management cases (Fig. 6c). Note that without full spatial management, as in the "spatial-tax" case, the imposition of any management reduces total effort levels relative to the unmanaged baseline.

All three management strategies produce tangible monetary gains over the unmanaged baseline case, in which unregulated open access reduces profits to zero in all locations under all conditions. The greater the degree of spatial control, the greater the tax-revenue gains: for all habitat sensitivities evaluated, "spatial-tax" revenues exceed "tax-and-reserve" revenues, which in turn exceed "nonspatial-tax" revenues (Fig. 6d). Although tax revenues decline for all management strategies as habitat sensitivity increases, the relative value of spatial knowledge is greater in more sensitive habitats. For example, when $\gamma=15$, a manager can approximately double his or her tax revenues by employing a "spatialtax" strategy instead of a "tax-and-reserve" or "nonspatial-tax" strategy.

\section{Alternative Boundary Conditions}

We originally designed our model on the assumption that fish could diffuse out of the habitat edges and be lost to the fishery. However, in reality, habitats may be bounded on one side (as by a shoreline), and fish may respond to environmental cues and avoid exiting the habitat. Thus, we also tested two sets of alternative boundary conditions: one set with a left reflecting boundary, and one set with two reflecting boundaries. We found that, although effort no longer fell to zero 

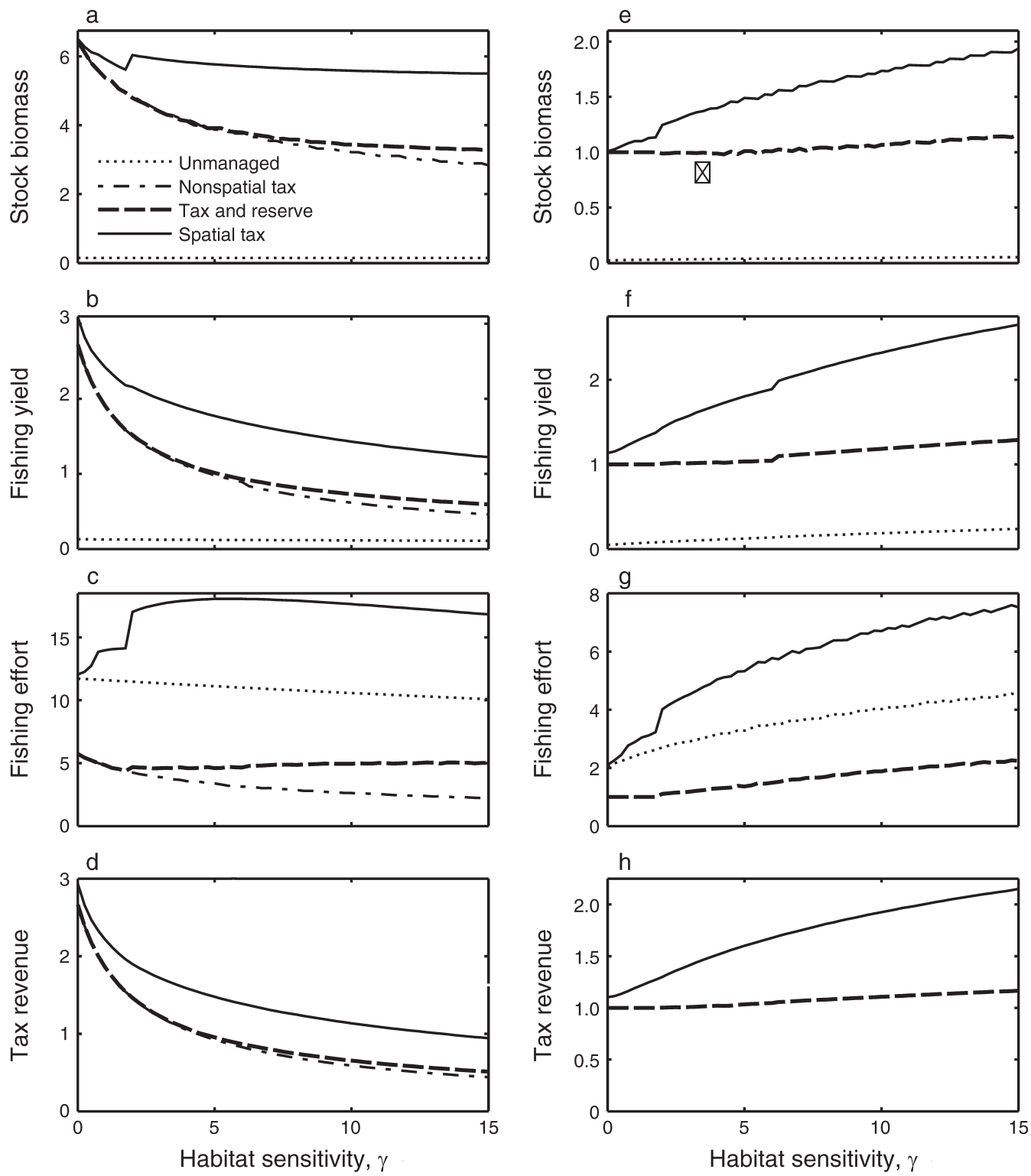

Fig. 6. Comparison of (a) stock biomass, (b) fishery yield, (c) fishing effort, and (d) tax revenue integrated over the entire habitat for four management scenarios: the unmanaged fishery (dotted line), the "nonspatial-tax" limited-management scenario (dash-dot line), the "tax-and-reserve" management scenario (dashed line), and the "spatial-tax" best-case management scenario (solid line). Stock biomass is the stock density integrated over the habitat. For all metrics of biological and economic fishery health, "spatial-tax" management produces the best results for all habitat sensitivities. (e-h) Relative increases (and decreases) in biomass, yield, fishing effort, and tax revenue compared to the "nonspatial-tax" strategy are also shown. Gains (rescaled values $>1$ ) can be ascribed to the value of spatial knowledge.

adjacent to closed boundaries (because diffusion did not drive fish biomass below economically viable levels), the reserve pattern was robust (Fig. 7).

When both habitat edges are closed (i.e., $\partial u / \partial x=0$ at $x=-\ell / 2$ and $x=\ell / 2)$, in the absence of fishing, habitat is of completely homogeneous quality. Intriguingly, even in this completely homogeneous case, reserves still emerge (Fig. 7k-o). This mathematically interesting result also suggests that our results should apply to fish with varying degrees of spatial awareness (i.e., fish that recognize habitat edges, and have the ability to remain within their habitats).

\section{Discussion}

Our results demonstrate that closing portions of habitat to fishing may be not just economically viable, but also economically beneficial, when fishing damages habitat. By considering habitat feedbacks from a 

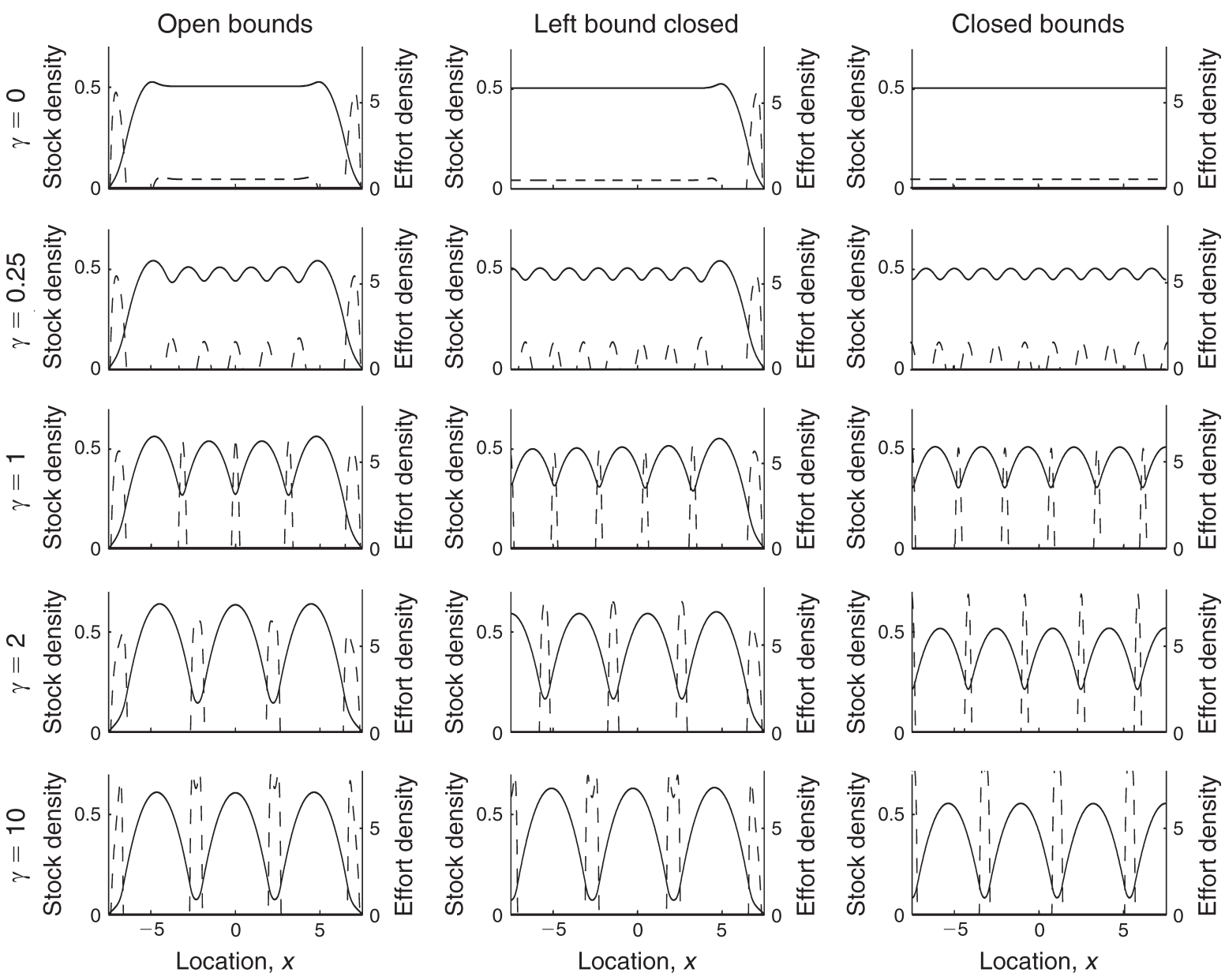

FIG. 7. The spatial distributions of biomass density (solid line) and effort (dashed line) under optimal "spatial tax" in response to varied boundary conditions: ( $\mathrm{a}-\mathrm{e}$ ) two open bounds, ( $\mathrm{f}-\mathrm{j}$ ) a single (left) reflecting bound, and (k-o) and two reflecting bounds. Results are shown for increasing density-independent habitat sensitivities, $\gamma$ (row $1, \gamma=0$; row $2, \gamma=0.25$; row 3 , $\gamma=1$; row $4, \gamma=2$; row $5, \gamma=10$ ); other parameter values are $\ell=15, \omega_{0}=0.01$, and $\omega_{1}=0.001$.

fundamentally economic perspective in continuous space, we are able to evaluate the consequences of increasing management control and to observe the emergence of reserve networks. Because our results explore the intersection of conservation and economic goals, they shed light on win-win scenarios and expand the conditions under which multiple benefits may arise from spatial closures (Neubert and Herrera 2008).

It is under first-best "spatial-tax" management conditions that reserve networks (unfished areas interspersed with shorter regions of high-intensity fishing effort) emerge. These networks persist even as habitat size increases (Fig. 5), suggesting that a spatial version of "pulse fishing" (see descriptions by Klerk and Gatto [1981] and McCallum [1988]) may be optimal in the presence of habitat effects.

The network pattern that emerges from the "spatialtax" analysis suggests that even limited management may be made more effective by designating more numerous, smaller reserves, rather than a single, central one. However, our study of second-best "tax-andreserve" management strategies shows that even single, central reserves may increase revenues, depending upon habitat size and sensitivity.

"Tax-and-reserve" combinations are optimal because they work together to protect a segment of fish habitat from damage and reduce effort outside of the reserve. Previous studies have found that constraints on fishing capacity are critical to maintaining optimal stock density and ensuring effectiveness of reserves (Hannesson 1998, Hiddink et al. 2006a). Under the "tax-and-reserve" management scenario studied above, we have seen how the optimal tax rate declines with increasing reserve fractions to balance the reduction in effort necessary from closing additional habitat to fishing.

Perhaps most importantly, we have seen that a spatial approach to fisheries management may produce significant gains in profit over nonspatial approaches (such as 


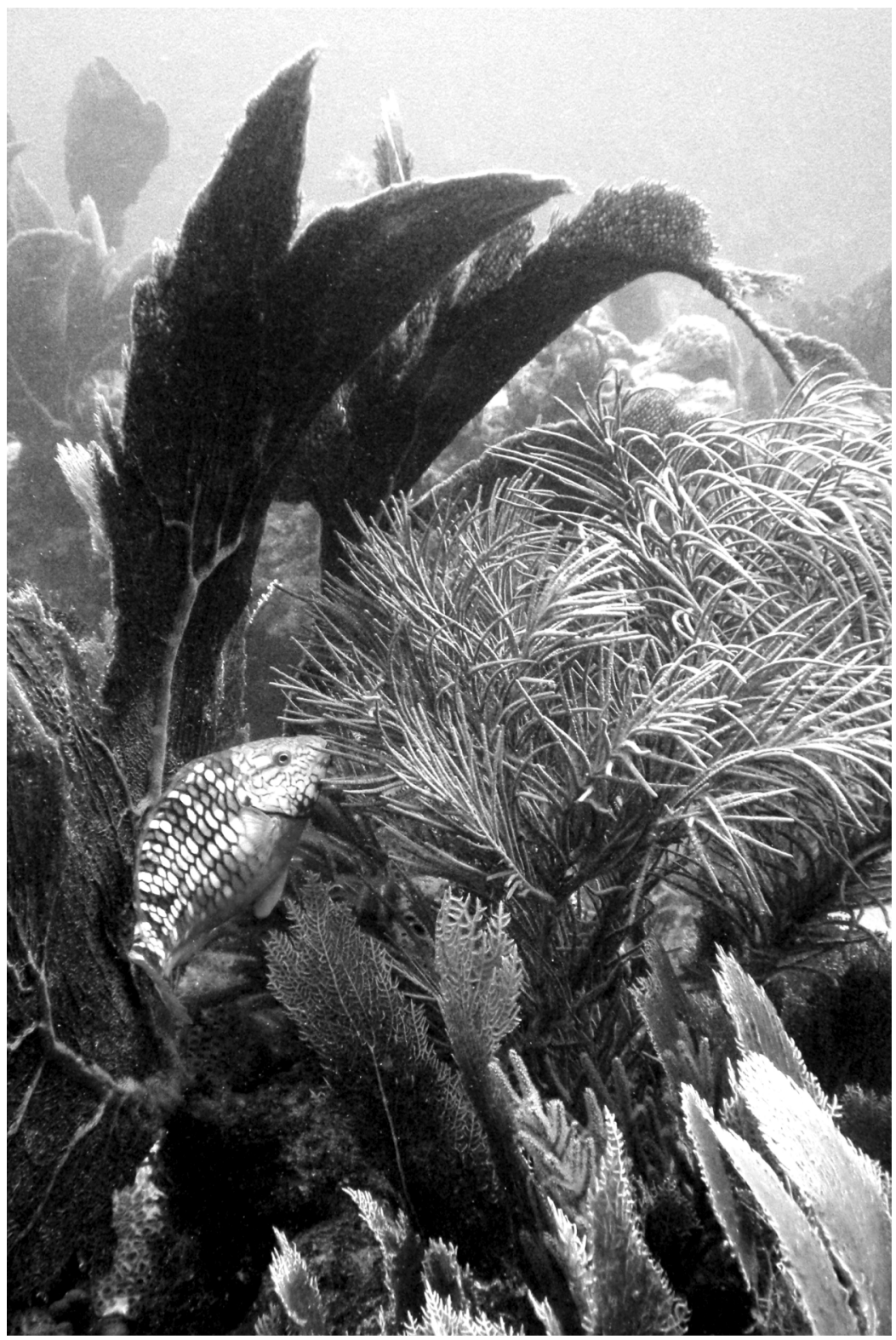

Plate 1. A stoplight parrotfish forages amid heterogeneous reef habitat in a Florida Keys marine reserve (USA). Reserves in Florida, and elsewhere in the Caribbean, are rich with diverse marine life. Photo credit: H. V. Moeller.

the "nonspatial-tax" case), especially in the first-best case of "spatial-tax" management. However, the relative differences between management outcomes depend upon habitat sensitivity, $\gamma$ : as $\gamma$ increases, the marginal gains from full spatial knowledge increase (see, especially, Fig. 6h). Studies in spatially heterogeneous systems have highlighted the relative economic gains from spatially optimized management (e.g., Rassweiler et al. 2012). Here, our results suggest a value for spatial knowledge (Costello et al. 2010) even when habitat is of homogeneous quality in the absence of fishing.

Thus spatially explicit management provides multiple economic and biological benefits: it allows for elevated total effort (potentially supporting increased employment in the fishery), total stock biomass, and total yield, while generating tax revenue in excess of any other management strategy (see also Neubert and Herrera 2008). This tax revenue may be retained by the manager to offset the costs of acquiring spatial knowledge or to offset enforcement costs, or may be returned through a variety of mechanisms to the fishing community as a way of encouraging cooperation with management programs (Cunningham 1994). Incentive-based management schemes (that aim to maintain sustainable, highlevel yields and can return tax to fishermen in the form of profits where profits were previously totally dissipat- 
ed) may be one route to improving fisheries management (Grafton et al. 2006).

Although full spatial control maximizes fishery revenue, when habitat sensitivity is sufficiently high it also calls for the enforcement of a reserve network. The extensive boundaries of such networks (relative to a single, larger reserve) have generally been seen as costly from an enforcement perspective (Halpern and Warner 2003, Roberts et al. 2003) because of the additional perimeter (per unit protected area) that must be patrolled. Indeed, some models include perimeter minimization in their reserve-siting algorithms (e.g., Leslie et al. 2003). In any real-world implementation of a reserve network like the one we describe here, a manager would therefore have to balance the relative economic gains of optimal spatial management with the relative costs of defending additional reserve perimeter. Although the economic and conservation gains of full spatial management relative to other management strategies rapidly become apparent with increasing habitat sensitivity (Fig. 6e,f), the truly optimal management scenario can only be chosen when enforcement costs are factored into management decisions.

In contrast to the results discussed above, under an alternative, density-independent formulation for habitat damage (see Appendix B), new marine reserves did not emerge as habitat sensitivity increased from $\gamma=0$. Thus, it is clear that the economic optimality of marine reserves is sensitive to model formulation. It is therefore important to gather information on the fishing gear in use, the habitat type and its response to fishing gear, and the mechanisms through which fish stocks grow, reproduce, and respond to habitat damage, before using models like this one to justify the establishment of marine reserves.

However, we emphasize that, regardless of management options or model formulation, as habitat sensitivity increases the manager faces inevitable declines in total stock biomass, fishery yield, and total tax revenue. Thus, optimal management may well include regulations to decrease habitat sensitivity, such as gear restrictions or spatial zoning to avoid more sensitive areas.

Further work is, of course, needed, particularly to address the spatial and temporal complexities of multistock and multi-use habitats. Here we have considered a single fish stock, when real-world reserve designation must account for the needs of multiple species. When species of conservation concern vary in their biology, and particularly in their dispersal capabilities, the orientation and spacing of reserves will necessarily be more complex. Additionally, present-day reserve implementations take place in habitats that have experienced a patchwork history of human usage, including fishing damage. To understand the optimal transition from various initial conditions to a sustainable policy requires analyses of dynamic spatial bioeconomic models (e.g., Brock and Xepapadeas 2008, 2010, Joshi et al. 2009) to account, for example, for habitat recovery.
This leads us to an important caveat pertaining to our results: the spatiotemporal distribution of effort that maximizes the present value of revenue over an infinite time horizon - call it the maximum economic yield of effort, $E_{\mathrm{MEY}}$ - may look quite different than the full spatial-control equilibrium solution we have calculated. The reasons are twofold. First, our analysis essentially ignores discounting and as a result ignores the potential costs of the transition to the steady state. Second, as a result of our equilibrium simplification, we were able to ignore the dynamic response of habitat quality to fishing pressure, as well as the dynamic response of the vital rates of the harvested population to habitat quality. Instead, we were able to jump directly to the equilibrium response of vital rates to fishing effort (Eq. 6). The dynamics of these responses will likely influence $E_{\mathrm{MEY}}$ in potentially complicated ways. In fact, $E_{\mathrm{MEY}}$ may not even asymptotically converge to an equilibrium distribution at all but rather depend on time as well as space.

Despite the aforementioned simplifications and caveats, our results provide additional evidence that ecological and economic benefits (applicable to both fishermen and managers) may result from implementing long-term spatial monitoring approaches. They also suggest the possibility that the implementation of spatial management strategies can be viewed as mutually beneficial to both conservation biologists and fishermen.

\section{ACKNOWLEDGMENTS}

The authors thank Hal Caswell, Guillermo Herrera, Julie Kellner, Martin Smith, three anonymous reviewers, and members of the 2010 ACKME Retreat for discussions and suggestions. M. G. Neubert acknowledges the support of the National Science Foundation (DMS-0532378, OCE-1031256) and a Thomas B. Wheeler Award for Ocean Science and Society. H. V. Moeller acknowledges support from a National Science Foundation Graduate Research Fellowship. This research is based in part on work supported by Award No. USA 00002 made by King Abdullah University of Science and Technology (KAUST). The views expressed in this paper are those of the authors and do not necessarily represent the official opinion of KAUST.

\section{Literature Cited}

Armstrong, C. W. 2007. A note on the ecological-economic modelling of marine reserves in fisheries. Ecological Economics 62:242-250.

Armstrong, C. W., and J. Falk-Petersen. 2008. Habitatfisheries interactions: a missing link? ICES Journal of Marine Science 65:817-821.

Armstrong, C. W., and A. Skonhoft. 2006. Marine reserves: a bio-economic model with asymmetric density dependent migration. Ecological Economics 57:466-476.

Auster, P. J. 1998. A conceptual model of the impacts of fishing gear on the integrity of fish habitats. Conservation Biology 12:1198-1203.

Brock, W., and A. Xepapadeas. 2008. Diffusion-induced instabiltiy and pattern formation in infinte horizon recursive optimal control. Journal of Economic Dynamics and Control 32:2745-2787.

Brock, W., and A. Xepapadeas. 2010. Pattern formation, spatial externalities and regulaton in coupled economicecological systems. Journal of Environmental Economics and Management 59:149-164. 
Costello, C., and S. Polasky. 2008. Optimal harvesting of stochastic spatial resources. Journal of Environmental Economics and Management 56:1-18.

Costello, C., A. Rassweiler, D. Siegel, G. D. Leo, F. Micheli, and A. Rosenberg. 2010. The value of spatial information in mpa network design. Proceedings of the National Academy of Sciences USA 107:18294-18299.

Cunningham, S. 1994. Fishermen's incomes and fisheries management. Marine Resource Economics 9:241-252.

Fogarty, M. J. 2005. Impacts of fishing activities on benthic habitat and carrying capacity: approaches to assessing and managing risk. American Fisheries Society Symposium 41:769-784.

Gårdmark, A., N. Jonzén, and M. Mangel. 2006. Densitydependent body growth reduces the potential of marine reserves to enhance yields. Ecology 43:61-69.

Gerber, L., L. Botsford, A. Hastings, H. P. Possingham, S. D. Gaines, S. R. Palumbi, and S. Andelman. 2003. Population models for marine reserve design: a retrospective and prospective synthesis. Ecological Applications 13:S47-S64.

Grafton, R. Q., T. Kompas, and P. V. Ha. 2006. The economic payoffs from marine reserves: resource rents in a stochastic environment. The Economic Record 82:469-480.

Halpern, B., and R. Warner. 2003. Matching marine reserve design to reserve objectives. Proceedings of the Royal Society B 270:1871-1878.

Hannesson, R. 1998. Marine reserves: what would they accomplish? Marine Resource Economics 13:159-170.

Hiddink, J., T. Hutton, S. Jennings, and M. J. Kaiser. $2006 a$. Predicting the effects of area closures and fishing effort restrictions on the production, biomass, and species richness of benthic invertebrate communities. ICES Journal of Marine Science 63:822-830.

Hiddink, J., S. Jennings, and M. J. Kaiser. 2007. Assessing and predicting the relative ecological impacts of disturbance on habitats with different sensitivities. Journal of Applied Ecology 44:405-413.

Hiddink, J., S. Jennings, M. J. Kaiser, A. Queirós, D. E. Duplisea, and G. J. Piet. 2006b. Cumulative impacts of seabed trawl disturbance on benthic biomass, production, and species richness in different habitats. Canadian Journal of Fisheries and Aquatic Science 63:721-736.

Holland, D., and K. E. Schnier. 2006. Individual habitat quotas for fisheries. Journal of Environmental Economics and Management 51:72-92.

Joshi, H. R., G. E. Herrera, S. Lenhart, and M. G. Neubert. 2009. Optimal dynamic harvest of a mobile renewable resource. Natural Resource Modeling 22:322-343.

Kellner, J. B., I. Tetreault, S. D. Gaines, and R. M. Nisbet. 2007. Fishing the line near marine reserves in single and multispecies fisheries. Ecological Applications 17:1039-1054.

Klerk, P. D., and M. Gatto. 1981. Some remarks on periodic harvesting of a fish population. Mathematical Biosciences $56: 47-69$

Leslie, H., M. Ruckelshaus, I. R. Ball, S. Andelman, and H. P. Possingham. 2003. Using siting algorithms in the design of marine reserve networks. Ecological Applications 13:S185S198.
Lester, S. E., B. S. Halpern, K. Grorud-Colvert, J. Lubchenco, B. I. Ruttenberg, S. D. Gaines, S. Airame, and R. R. Warner. 2009. Biological effects within no-take marine reserves: a global synthesis. Marine Ecology Progress Series 384:33-46.

Lindholm, J. B., P. J. Auster, M. Ruth, and L. Kaufman. 2001. Modeling the effects of fishing and implications for the design of marine protected areas: juvenile fish responses to variations in seafloor habitat. Conservation Biology 15:424-437.

Mangel, M. 2000. Trade-offs between fish habitat and fishing mortality and the role of reserves. Bulletin of Marine Science 66:663-674.

McCallum, H. 1988. Pulse fishing may be superior to selective fishing. Mathematical Biosciences 89:177-181.

National Research Council. 2001. Marine protected areas: tools for sustaining ocean ecosystems. National Academy Press, Washington, D.C., USA.

Neubert, M. 2003. Marine reserves and optimal harvesting. Ecology Letters 6:843-849.

Neubert, M. G., and G. E. Herrera. 2008. Triple benefits from spatial resource management. Theoretical Ecology 1:5-12.

Rassweiler, A., C. Costello, and D. A. Siegel. 2012. Marine protected areas and the value of spatially optimized fishery management. Proceedings of the National Academy of Sciences USA 109(29):11884-11889.

Roberts, C. M., et al. 2003. Ecological criteria for evaluating candidate sites for marine reserves. Ecological Applications 13:S199-S214.

Rodwell, L. D., E. B. Barbier, C. M. Roberts, and T. R. McClanahan. 2003. The importance of habitat quality for marine reserve-fishery linkages. Canadian Journal of Fisheries and Aquatic Science 60:171-181.

Sanchirico, J. N. 2004. Designing a cost-effective marine reserve network: a bioeconomic metapopulation analysis. Marine Resource Economics 19:41-65.

Sanchirico, J. N., U. Malvadkar, A. Hastings, and J. E. Wilen. 2006. When are no-take zones an economically optimal fishery management strategy? Ecological Applications 16:1643-1659.

Sanchirico, J. N., and J. E. Wilen. 1999. Bioeconomics of spatial exploitation in a patchy environment. Journal of Environmental Economics and Management 37:129-150.

Sinclair, A. 1989. Population regulation in animals. Pages 197241 in J. M. Cherrett, editor. Ecological concepts: the contribution of ecology to an understanding of the natural world. The 29th Symposium of the British Ecological Society. Blackwell Scientific Publications, Oxford, UK.

Smith, M. D., and J. E. Wilen. 2003. Economic impacts of marine reserves: the importance of spatial behavior. Journal of Environmental Economics and Management 46:183-206.

Watling, L., and E. A. Norse. 1998. Disturbance of the seabed by mobile fishing gear: A comparison to forest clearcutting. Conservation Biology 12:1180-1197.

White, C., and B. E. Kendall. 2007. A reassessment of equivalence in yield from marine reserves and traditional fisheries management. Oikos 116:2039-2043.

\section{Supplemental Material}

\section{Appendix A}

Analysis of the spatial effort tax model (Ecological Archives A023-049-A1). 